\title{
Pleurotus ostreatus opposes mitochondrial dysfunction and oxidative stress in acetaminophen-induced hepato-renal injury
}

Yahya M Naguib ${ }^{1 *}$, Rania M Azmy², Rehab M Samaka ${ }^{3}$ and Mohamed F Salem ${ }^{4}$

\begin{abstract}
Background: Acetaminophen (APAP)-induced toxicity is a predominant cause of acute hepatic and renal failure. In both humans and rodents toxicity begins with a reactive metabolite that binds to proteins. This leads to mitochondrial dysfunction and nuclear DNA fragmentation resulting in necrotic cell death. Pleurotus ostreatus (an edible oyster mushroom) is well recognized as a flavourful food, as well as a medicinal supplement. In the present study, we evaluated the role of Pleurotus ostreatus in the protection against APAP-induced hepato-renal toxicity. We also explored the mechanism by which Pleurotus ostreatus exerts its effects.

Methods: Ninety adult male Swiss albino mice were divided into three groups (30 mice/group). Mice were offered normal diet (control and APAP groups), or diet supplemented with 10\% Pleurotus ostreatus (APAP + Pleurotus ostreatus) for 10 days. Mice were either treated with vehicle (control group, single intra-peritoneal injection.), or APAP (APAP and APAP + Pleurotus ostreatus groups, single intra-peritoneal injection, $500 \mathrm{mg} / \mathrm{kg}$ ), 24 hours after the last meal.

Results: APAP increased serum levels of alanine aminotransferase (ALT), aspartate aminotransferase (AST) glutamate dehydrogenase $(\mathrm{GDH})$, creatinine, blood urea nitrogen (BUN), urinary kidney injury molecule-1 (KIM-1), and hepatic and renal malondialdehyde (MDA) content. APAP decreased hepatic and renal glutathione (GSH) content, as well as glutathione peroxidase (GSH-Px) and superoxide dismutase (SOD) activities. Supplementation with Pleurotus ostreatus significantly reduced APAP-induced elevated levels of ALT, AST, GDH, creatinine, BUN, KIM-1and MDA, while GSH level, and GSH-Px and SOD activities were significantly increased. Our findings were further validated by histopathology; treatment with Pleurotus ostreatus significantly decreased APAP-induced cell necrosis in liver and kidney tissues.
\end{abstract}

Conclusions: We report here that the antioxidant effect of Pleurotus ostreatus opposes mitochondrial dysfunction and oxidative stress accompanying APAP over-dose, with subsequent clinically beneficial effects on liver and kidney tissues.

Keywords: Pleurotus ostreatus, Oxidative stress, Acute hepato-renal injury, Mitochondrial dysfunction, Acetaminophen, Antioxidant

\footnotetext{
* Correspondence: yahya.naguib@med.menofia.edu.eg

'Department of Clinical Physiology, Faculty of Medicine, Menoufia University, Menoufia, Egypt

Full list of author information is available at the end of the article
} 


\section{Background}

Acetaminophen ( $\mathrm{N}$ - acetyl-p-aminophenol, APAP) is a widely prescribed non-narcotic analgesic and antipyretic drug. APAP is commonly sold in the clinic as well as numerous over-the-counter preparations either as a single compound or in combination with other drugs [1-3]. APAP is metabolized by cytochrome P450 (CYP) to form the highly reactive species, $N$-acetyl- $p$-benzoquinone imine (NAPQI), which under normal conditions is readily detoxified by conjugation with glutathione (GSH). However, an overdose of APAP can lead to severe liver and/or kidney injury in humans and in experimental animals $[4,5]$. Most importantly, in the presence of hepatic, renal or cardiopulmonary insufficiency, even therapeutic doses of APAP may cause hepato-renal damage [6,7]. High doses of APAP saturate the detoxification pathways [8]; depletion of GSH leaves NAPQI free to bind to possibly critical cellular proteins and cause cell necrosis. Therefore, APAP toxicity is determined by the amount of NAPQI produced and the insufficient availability of GSH for APAP detoxification [9-11].

Reactive oxygen species (ROS) are fundamentally correlated to oxidative stress. ROS have been implicated in a number of disease processes, including hepatic injury, renal injury, cardiac diseases, neurodegenerative diseases, diabetes, pulmonary diseases as well as cancer [12-20]. Maintaining the balance between the production of ROS and the availability of antioxidant enzymes, such as superoxide dismutase (SOD), catalase (CAT), and glutathione peroxidase (GPx), is consequently critical. This could be an important mechanism for preventing the oxidative stressinduced tissue damage. ROS-antioxidants balance has been suggested to have an important role in the development of APAP toxicity [5]. Lipid peroxidation, mediated by ROS, is believed to be an important cause of cell membranes damage. The role of ROS in mediating the microvascular disturbances that precede tissue damage induced by various chemicals has gained much attention. It has been shown that, during APAP intoxication in the mouse, toxic ROS are generated and actively participate in the pathophysiological process leading to hepatocyte necrosis [4].

Scientific and clinical interests have risen towards the use of mushrooms with potential therapeutic effects. Edible mushrooms are a valuable source of biologically active compounds. The medicinal potential of edible mushrooms arises from the fact that they are natural, less expensive and have minimal side effects. Mushrooms demonstrate their efficiency against numerous diseases and metabolic disturbances. These therapeutic effects seem to be underlined by multiple complex cellular and molecular actions [21]. Pleurotus ostreatus (an oyster mushroom) is one of the widely cultivated edible mushrooms. Pleurotus ostreatus demonstrated antioxidative, hypocholesterolemic, and antiatherogenic activities [22]. Antitumor properties [23], as well as the ability to enhance the immune system have also been reported [24].

In the present study, we aimed to evaluate the protective effects of Pleurotus ostreatus on APAP-induced hepatorenal toxicity in mice, with emphasis on mitochondrial dysfunction trying to elucidate the mechanism(s) by which Pleurotus ostreatus may execute its protective effect.

\section{Methods}

\section{Animals}

Ninety male Swiss albino mice, 10-14 weeks old weighing approximately 20-25 g, were used in the present study. Mice were maintained under controlled temperature, humidity, and 12 hour light/dark cycles. The animals were fed standard rodent chow and allowed free access to water ad libitum, and were kept for 10 days prior to any procedure to allow proper acclimatization. Animal care and use was approved by the Ethics Committee of Faculty of Medicine-Menoufia University-Egypt. The experiments were carried in accordance with the Guide for the Care and Use of Laboratory Animals published by the US National Institutes of Health (NIH Publication no. 85-23, revised in 1996).

After acclimatization, mice were divided randomly into the following groups (30 mice/group): (1) control group, (2) APAP group, and (3) APAP + Pleurotus ostreatus group. Mice in the control and APAP groups were fed normal rodent diet; while those in the APAP + Pleurotus ostreatus group were fed normal rodent diet supplemented with $10 \%$ Pleurotus ostreatus for 10 consecutive days. Mice were fasted for 12 hours before treatment with APAP or vehicle as indicated. Acute liver injury was induced in APAP and APAP + Pleurotus ostreatus groups by a single intra-peritoneal (i.p) injection of $500 \mathrm{mg} / \mathrm{kg}$ APAP (SigmaAldrich Co., Mo, USA) dissolved in warm phosphatebuffered saline (PBS, pH 7.4). Control mice were injected with equal volumes of the vehicle.

Five mice from each group were scarified either just before (0), or after (1, 2 and 8) hours following APAP or vehicle treatment. The aim of the separate experiment was to validate the anti-oxidant properties of Pleurotus ostreatus.

\section{Collection of oyster mushroom}

Mature fruiting bodies of Pleurotus ostreatus were kind gift from Dr Mohamed F Salem (Genetic Engineering and Biotechnology Research Institute, Sadat City University, Egypt). The fruiting bodies were dried in sunlight and crushed into powder. The powder was mixed with the basal diet.

\section{Characterization of oyster mushroom dried powder}

Protein, fat and ash contents were determined using standard analytical methods [25]. Total dietary fiber 
(TDF) constituted the sum of soluble and insoluble dietary fiber and was determined using enzymatic method [26]. Analytical determinations were conducted in three independent replications and the results are presented in grams per $100 \mathrm{~g}$ dry powder.

The amino acid composition was identified as described previously [27]. High performance liquid chromatography (HPLC) analysis was carried out in an Agilent 1220 Infinity system (Santa Clara, CA, USA). The amino acid composition was expressed as percentage of protein.

\section{Blood and tissue samples collection}

All mice were scarified 24 hours after APAP injection. Blood was drawn from each mouse via cardiac puncture. The blood was allowed to coagulate for 30 minutes at room temperature. Blood samples were then centrifuged at $2000 \mathrm{rpm}$ for $10 \mathrm{~min}$ to separate serum samples. Serum samples were stored at $-20^{\circ} \mathrm{C}$. Serum samples were used for the estimation alanine aminotransferase (ALT), aspartate aminotransferase (AST), glutamate dehydrogenase $(\mathrm{GDH})$, creatinine and blood urea nitrogen (BUN).

The liver and kidneys were carefully dissected from the fat and connective tissue. The tissues were rinsed several times with cold saline and air dried on filter paper. Liver and kidney specimens were used for the preparation of tissue homogenates and tissue slides for Haematoxylin and Eosin (Hx \& E) stain.

\section{Urine samples collection}

Urine samples from the mice were collected on day 1 after disease induction. 24-hour urine collection using metabolic cages was carried out for all mice. All collected urine samples were aliquoted and frozen away.

\section{Preparation of tissue homogenates}

Specimens from the liver and kidney were weighted and homogenized separately with tissue homogenizer (MPW120, MPW Medical Instruments, China). For estimation of tissue glutathione (GSH), malondialdehyde (MDA) levels and the activities of glutathione peroxidise (GSH-Px), tissues were homogenized in phosphate buffer saline (PBS) $50 \mathrm{mM} \mathrm{pH} \mathrm{7.4.} \mathrm{For} \mathrm{estimation} \mathrm{of} \mathrm{superoxide} \mathrm{dismutase}$ (SOD) tissues were homogenized in potassium phosphate buffer (PPB) $10 \mathrm{mM} \mathrm{pH} \mathrm{7.4.} \mathrm{The} \mathrm{crude} \mathrm{tissue} \mathrm{homogenate}$ was centrifuged at 10,000 rpm, for 15 minutes in ice-cold centrifuge, and the resultant supernatant was collected and stored at $-20^{\circ} \mathrm{C}$.

\section{Measurement of APAP protein adducts in liver tissue homogenate}

Measurement of APAP-cysteine (APAP-CYS) in liver tissue homogenate was performed using high pressure liquid chromatography with electrochemical detection (HPLCECD) as described previously [28].

\section{Biochemical analysis}

Serum levels of alanine aminotransferase (ALT), aspartate aminotransferase (AST), creatinine and blood urea nitrogen (BUN) (ELITech, France), and glutamate dehydrogenase (GDH) (QuantiChrom ${ }^{\mathrm{Tm}}$, BioAssay Systems, USA) were determined by routine kinetic and fixed rate colorimetric methods on a Jenway Genova autoanalyser (UK) [29-31].

Urinary kidney injury molecule-1 (KIM-1) was measured by a highly sensitive two-site enzyme linked immunoassay (ELISA) (ALPCO Diagnostics, USA) [32,33].

Tissue levels of glutathione (GSH) and malondialdehyde (MDA) (QuantiChrom ${ }^{\mathrm{Tm}}$, BioAssay Systems, USA), glutathione peroxidase (GSH-Px) and superoxide dismutase (SOD) (EnzyChrom ${ }^{\text {тм }}$, BioAssay Systems, USA), were determined by colorimetric method [34-37].

\section{Haematoxylin and Eosin (Hx \& E) stain}

Specimens from the liver and kidney were fixed in $10 \%$ formol saline for 5-7 days. The specimens were washed in tap water for 10 minutes and then dehydrated in graded ethanol solutions (70\%, 90\% over night and 100\% ethanol solution for three changes one hour each). The specimens were cleared in xylene (20-30 times). After that, specimens were impregnated in soft paraffin wax at $55-60^{\circ} \mathrm{C}$ for two hours then in hard paraffin wax at room temperature in moulds. Tissue blocks were cut into section of 5 microns thickness by using rotator microtome. Tissue sections were dipped in a warm water-bath, picked up on clean slides, and placed on hot plate for two minutes. Finally, tissue sections were stained with haematoxylin and eosin stain for general architecture of the studied tissues.

\section{Statistical analysis}

Results are expressed as mean \pm standard error (SE). Student t-test or repeated-measures Analysis of Variances (ANOVA) were used for statistical analysis of the different groups whichever appropriate, using Origin ${ }^{\circledR}$ software and the probability of chance ( $\mathrm{p}$ values). $\mathrm{P}$ values $<0.05$ were considered significant.

\section{Results}

Serum ALT increased significantly in the APAP-treated group when compared to the control group (710.5 \pm 25.8 vs $60.7 \pm 8.2 \mathrm{IU}, \mathrm{P}<0.05)$. Serum ALT levels were significantly lower in the APAP + Pleurotus ostreatus group than that in the APAP group $(67.4 \pm 8.2 \mathrm{IU}, \mathrm{P}<0.05)$. There was no statistically significant difference in serum ALT between APAP + Pleurotus ostreatus and control groups $(\mathrm{P}>0.05)$ (Figure $1 \mathrm{~A})$.

Serum AST increased significantly in the APAP-treated group when compared to the control group $(645.7 \pm 30.8$ vs $72.4 \pm 11.2 \mathrm{IU}, \mathrm{P}<0.05)$. Serum AST levels were significantly lower in the APAP + Pleurotus ostreatus group than 

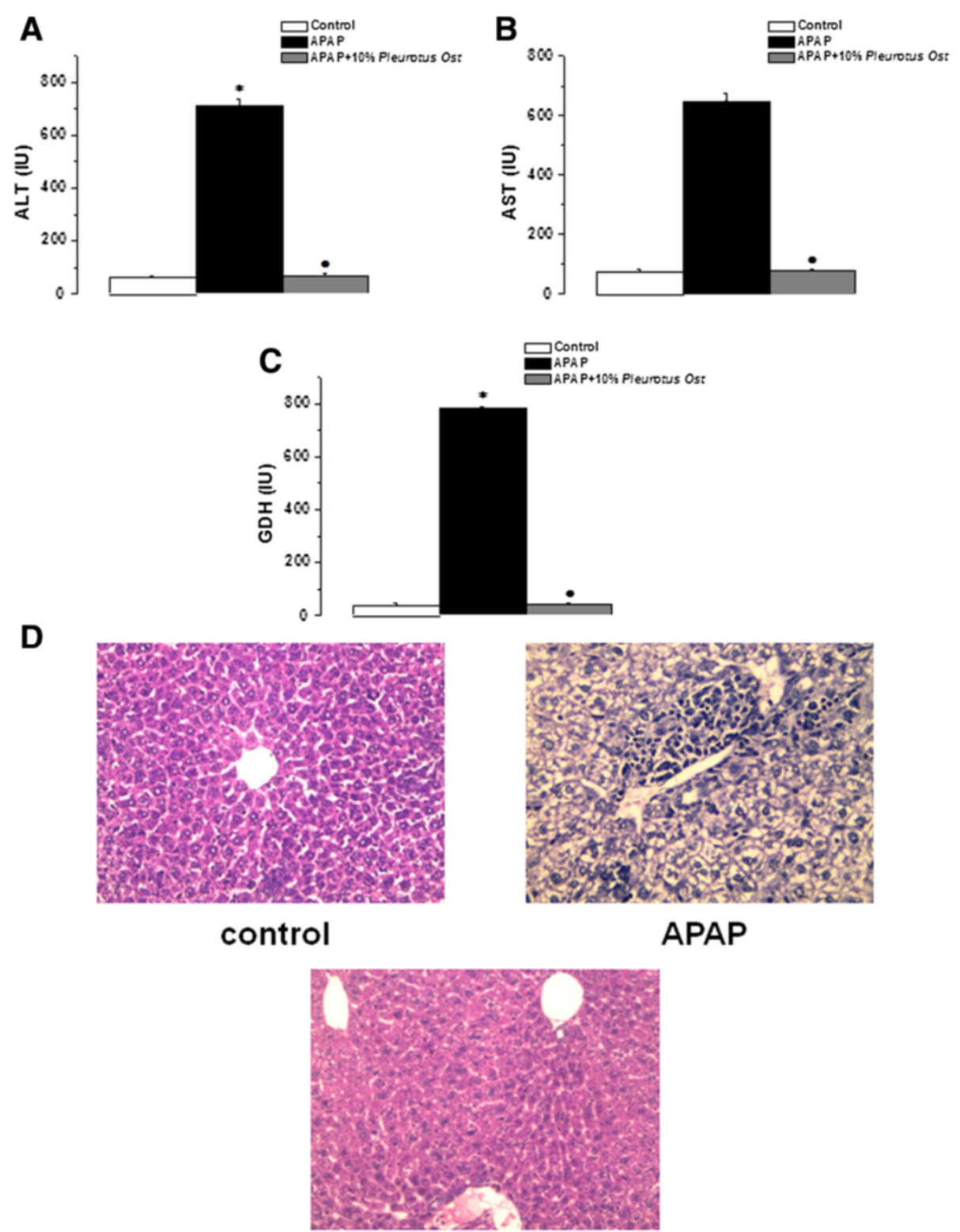

\section{APAP+10\% Pleurotus Ost}

Figure 1 Pleurotus ostreatus protects against liver injury in APAP-overdose treated mice. (A) Serum ALT levels in control (white column), APAP treated (black column) and APAP + 10\% Pleurotus ostreatus treated (grey column) groups. (B) Serum AST levels in control (white column), APAP treated (black column) and APAP + 10\% Pleurotus ostreatus treated (grey column) groups. (C) Serum GDH levels in control (white column), APAP treated (black column) and APAP $+10 \%$ Pleurotus ostreatus treated (grey column) groups. (D) Representative photomicrograph of Hx \& E stained liver sections from control, APAP treated and APAP $+10 \%$ Pleurotus ostreatus treated mice $(\times 400)$. (Significant $=p<0.05,{ }^{*}$ significant when compared to the control group, $\cdot$ significant when compared to the APAP treated group. Number of mice $=10 /$ group).

that in the APAP group $(77.4 \pm 8.3 \mathrm{IU}, \mathrm{P}<0.05)$. There was no statistically significant difference in serum AST between APAP + Pleurotus ostreatus and control groups $(\mathrm{P}>0.05)$ (Figure 1B).

Serum GDH increased significantly in the APAP-treated group when compared to the control group $(782.6 \pm 36.5$ vs $38.9 \pm 6.3 \mathrm{IU}, \mathrm{P}<0.05)$. Serum GDH levels were significantly lower in the APAP + Pleurotus ostreatus group than that in the APAP group $(41.7 \pm 7.2 \mathrm{IU}, \mathrm{P}<0.05)$. There was no statistically significant difference in serum GDH between APAP + Pleurotus ostreatus and control groups $(\mathrm{P}>0.05)$ (Figure 1C).

The appearance of liver tissues 24 hours after APAP injection was confirmed by histopathological observation. Centrilobular necrosis, sinusoidal congestion, lymphocytes infiltration and Kupffer cells around the central vein, loss 
of cell boundaries and ballooning degeneration were observed after administration of acetaminophen. However, mice treated with $10 \%$ Pleurotus ostreatus preserved normal hepatic architecture with minimal changes (Figure 1D).

Serum creatinine increased significantly in the APAPtreated group when compared to the control group (1.26 \pm 0.25 vs $0.31 \pm 0.08 \mathrm{IU}, \mathrm{P}<0.05)$. Serum creatinine levels were significantly lower in the APAP + Pleurotus ostreatus group than that in the APAP group $(0.34 \pm 0.09 \mathrm{IU}, \mathrm{P}<$ $0.05)$. There was no statistically significant difference in serum creatinine between APAP + Pleurotus ostreatus and control groups $(\mathrm{P}>0.05)$ (Figure $2 \mathrm{~A})$.

Serum BUN increased significantly in the APAP-treated group when compared to the control group $(98.4 \pm 6.7 \mathrm{vs}$
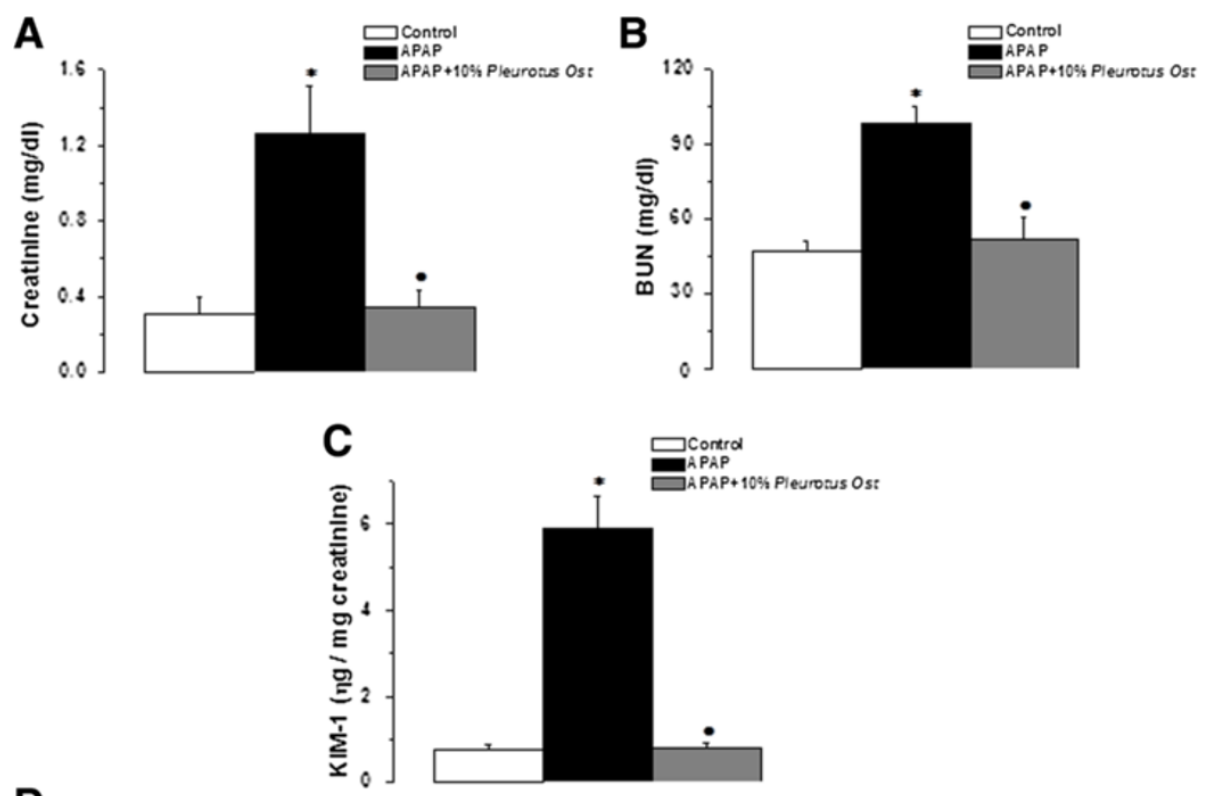

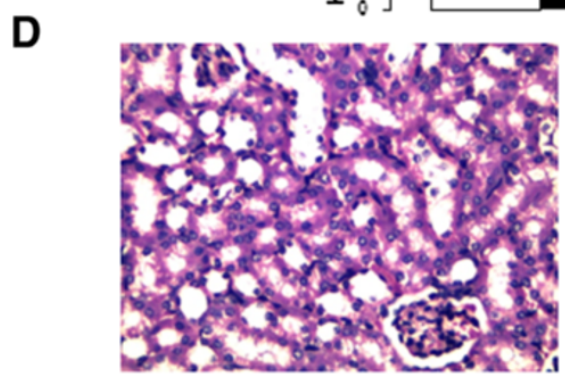

control

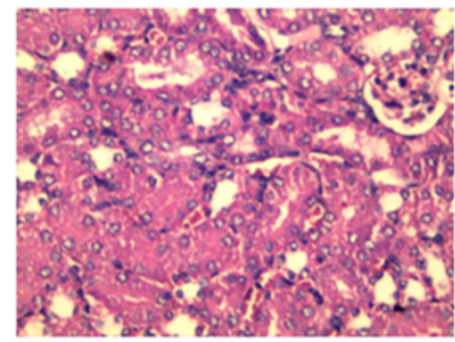

APAP

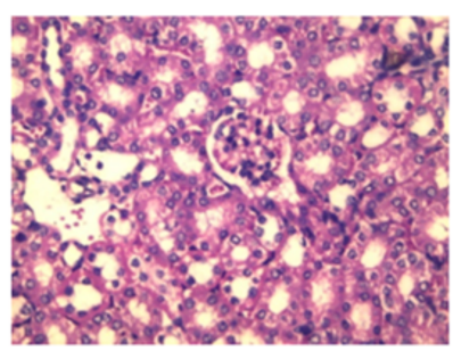

APAP+10\% Pleurotus Ost

Figure 2 Pleurotus ostreatus protects against kidney injury in APAP-overdose treated mice. (A) Serum creatinine levels in control (white column), APAP treated (black column) and APAP + 10\% Pleurotus ostreatus treated (grey column) groups. (B) Serum BUN levels in control (white column), APAP treated (black column) and APAP + 10\% Pleurotus ostreatus treated (grey column) groups. (C) Urinary KIM-1 levels in control (white column), APAP treated (black column) and APAP + 10\% Pleurotus ostreatus treated (grey column) groups. (D) Representative photomicrograph of Hx \& E stained kidney sections from control, APAP treated and APAP $+10 \%$ Pleurotus ostreatus treated mice $(\times 400)$. (Significant $=p<0.05$, * significant when compared to the control group, $\bullet$ significant when compared to the APAP treated group. Number of mice $=10 /$ group). 
$47.3 \pm 4.2 \mathrm{IU}, \mathrm{P}<0.05)$. Serum BUN levels were significantly lower in the APAP + Pleurotus ostreatus group than that in the APAP group $(51.7 \pm 9.2 \mathrm{IU}, \mathrm{P}<0.05)$. There was no statistically significant difference in serum BUN between APAP + Pleurotus ostreatus and control groups $(\mathrm{P}>0.05)$ (Figure 2B).

Urinary KIM-1 increased significantly in the APAPtreated group when compared to the control group (5.91 \pm 0.76 vs $0.78 \pm 0.11 \mathrm{ng} / \mathrm{mg}$ creatinine, $\mathrm{P}<0.05)$. Urinary KIM-1 levels were significantly lower in the APAP + Pleurotus ostreatus group than that in the APAP group $(0.81 \pm 0.18 \eta \mathrm{g} / \mathrm{mg}$ creatinine, $\mathrm{P}<0.05)$. There was no statistically significant difference in Urinary KIM-1 between APAP + Pleurotus ostreatus and control groups $(\mathrm{P}>0.05)$ (Figure 2C).

Histopathological appearance of kidney tissues 24 hours after APAP injection showed focal area of coagulative necrosis and haemorrhage. Necrotic areas demonstrated ghosts of renal tubules, casts and lymphocytic infiltrates.
The necrotic areas were sharply separated from the adjacent normal renal tissue. However, no such changes were evident in the kidneys of mice treated with $10 \%$ Pleurotus ostreatus (Figure 2D).

Hepatic GSH was significantly lower in the APAP group when compared to the control group $(2.9 \pm 0.32$ vs $10.1 \pm$ $1.6 \mu \mathrm{M} / \mathrm{mg}$ protein, $\mathrm{P}<0.05)$. Hepatic GSH in APAP + Pleurotus ostreatus group was significantly higher than in the APAP group $(9.16 \pm 0.49 \mu \mathrm{M} / \mathrm{mg}$ protein, $\mathrm{P}<0.05)$. There was no statistically significant difference in hepatic GSH between APAP + Pleurotus ostreatus and control groups $(\mathrm{P}>0.05)$. Renal GSH was significantly lower in the APAP group compared to the control group (3.3 \pm 0.64 vs $6.1 \pm 1.2 \mu \mathrm{M} / \mathrm{mg}$ protein, $\mathrm{P}<0.05)$. Renal GSH in APAP + Pleurotus ostreatus group was significantly higher than in the APAP group $(5.9 \pm 1.1 \mu \mathrm{M} / \mathrm{mg}$ protein, $\mathrm{P}<$ $0.05)$. There was no statistically significant difference in renal GSH between APAP + Pleurotus ostreatus and control groups $(\mathrm{P}>0.05)$ (Figure $3 \mathrm{~A})$.
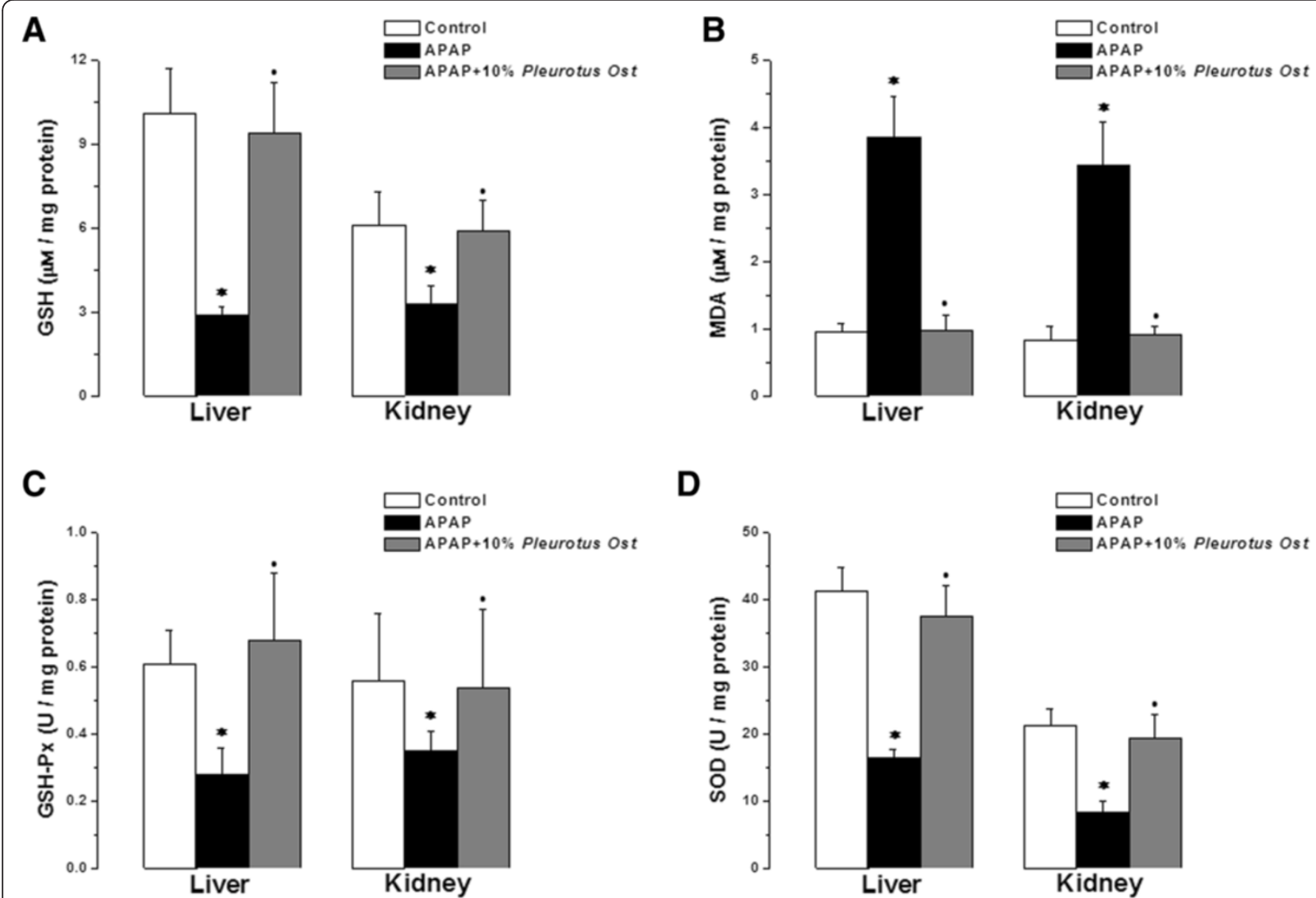

D

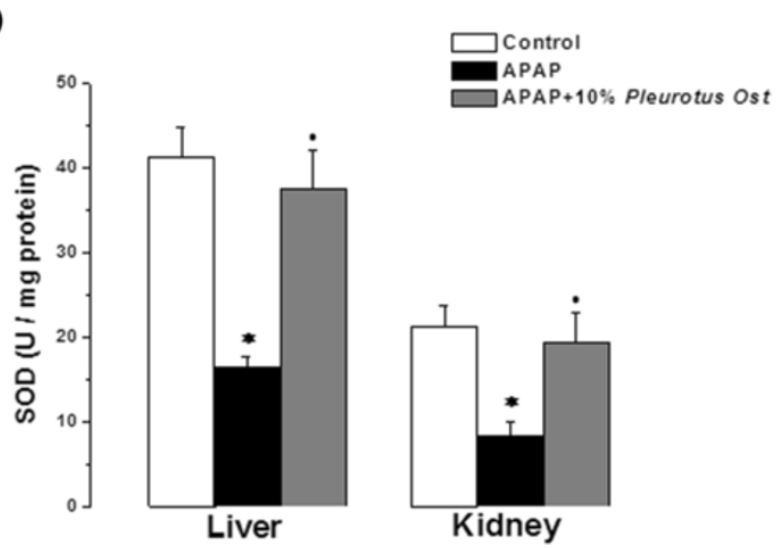

Figure 3 Anti-oxidant properties of Pleurotus ostreatus. (A) Liver and kidney GSH levels in control (white column), APAP treated (black column) and APAP $+10 \%$ Pleurotus ostreatus treated (grey column) groups. (B) Liver and kidney MDA levels in control (white column), APAP treated (black column) and APAP + 10\% Pleurotus ostreatus treated (grey column) groups. (C) Liver and kidney GSH-Px levels in control (white column), APAP treated (black column) and APAP + 10\% Pleurotus ostreatus treated (grey column) groups. (D) Liver and kidney SOD levels in control (white column), APAP treated (black column) and APAP $+10 \%$ Pleurotus ostreatus treated (grey column) groups. (Significant $=p<0.05$, * significant when compared to the control group, $\bullet$ significant when compared to the APAP treated group. Number of mice $=10 /$ group). 
Hepatic MDA was elevated significantly in the APAP group when compared to the control group $(3.86 \pm 0.61$ vs $0.97 \pm 0.12 \mu \mathrm{M} / \mathrm{mg}$ protein, $\mathrm{P}<0.05)$. Hepatic MDA in APAP + Pleurotus ostreatus group was significantly lower than in the APAP group $(0.99 \pm 0.23 \mu \mathrm{M} / \mathrm{mg}$ protein, $\mathrm{P}<$ $0.05)$. There was no statistically significant difference in hepatic MDA between APAP + Pleurotus ostreatus and control groups $(\mathrm{P}>0.05)$. Renal MDA was significantly elevated in the APAP group when compared to the control group $(3.45 \pm 0.65$ vs $0.83 \pm 0.21 \mu \mathrm{M} / \mathrm{mg}$ protein, $\mathrm{P}<0.05)$. Renal MDA in APAP + Pleurotus ostreatus group was significantly lower than in the APAP group (0.91 \pm $0.13 \mu \mathrm{M} / \mathrm{mg}$ protein, $\mathrm{P}<0.05)$. There was no statistically significant difference in renal MDA between APAP + Pleurotus ostreatus and control groups $(\mathrm{P}>0.05)$ (Figure $3 \mathrm{~B})$.

Hepatic GSH-Px activity was significantly lower in the APAP group when compared to the control group $(0.29 \pm$ 0.08 vs $0.61 \pm 0.1 \mathrm{U} / \mathrm{mg}$ protein, $\mathrm{P}<0.05)$. Hepatic $\mathrm{GSH}-$ Px activity in APAP + Pleurotus ostreatus group were significantly higher than in the APAP group $(0.60 \pm 0.2 \mathrm{U} / \mathrm{mg}$ protein, $\mathrm{P}<0.05)$. There was no statistically significant difference in hepatic GSH-Px activity between APAP + Pleurotus ostreatus and control groups $(\mathrm{P}>0.05)$. Renal GSH-Px activity was significantly lower in the APAP group when compared to the control group $(0.35 \pm 0.06$ vs $0.56 \pm 0.02 \mathrm{U} / \mathrm{mg}$ protein, $\mathrm{P}<0.05)$. Renal GSH-Px activity in APAP + Pleurotus ostreatus group was significantly higher than in the APAP group $(0.54 \pm 0.23 \mathrm{U} / \mathrm{mg}$ protein, $\mathrm{P}<0.05)$. There was no statistically significant difference in renal GSH-Px activity between APAP + Pleurotus ostreatus and control groups $(\mathrm{P}>0.05)$ (Figure $3 \mathrm{C})$.

Hepatic SOD activity was significantly lower in the APAP group when compared to the control group (16.4 \pm 1.3 vs $41.3 \pm 3.5 \mathrm{U} / \mathrm{mg}$ protein, $\mathrm{P}<0.05)$. Hepatic SOD activity in APAP + Pleurotus ostreatus group was significantly higher than in the APAP group $(37.6 \pm 4.5 \mathrm{U} / \mathrm{mg}$ protein, $\mathrm{P}<0.05)$. There was no statistically significant difference in hepatic SOD activity between APAP + Pleurotus ostreatus and control groups $(\mathrm{P}>0.05)$. Renal SOD activity was significantly lower in the APAP group when compared to the control group $(8.4 \pm 1.6$ vs $21.3 \pm 2.4 \mathrm{U} / \mathrm{mg}$ protein, $\mathrm{P}<0.05)$. Renal SOD activity in APAP + Pleurotus ostreatus group was significantly higher than in the APAP group $(19.3 \pm 3.6 \mathrm{U} / \mathrm{mg}$ protein, $\mathrm{P}<0.05)$. There was no statistically significant difference in renal SOD activity between APAP + Pleurotus ostreatus and control groups $(\mathrm{P}>0.05)$ (Figure $3 \mathrm{D})$.

In a separate experiment, 5 mice from each group were scarified just before (0), or after 1, 2 and 8 hours following APAP or vehicle treatment. APAP-CYS adducts and GSH depletion was measured in liver tissue homogenate, while hepatocyte injury was monitored by measuring serum ALT (Figure 4). Pre-treatment with Pleurotus ostreatus did not alter the metabolic activation of APAP as indicated by the insignificant change in APAP-CYS adducts formation at 1, 2 and 8 (Figure 4A). Simultaneously, Pleurotus ostreatus treatment restored APAP-induced GSH depletion 8 hours after APAP treatment (Figure 4B). Hepatocyte injury was only evident after 8 hours following APAP treatment as indicated by serum ALT level (Figure 4C).

\section{Discussion}

Pleurotus ostreatus or its constituents have been reported to possess potent antioxidant, antihypercholesterolemic, immunomodulatory and anticancer properties [22-24]. However, potential hepatoprotective or nephroprotective effects and the possible involvement of antioxidant properties as the underlying mechanism have not been reported. Up to our knowledge, we report here for the first time that Pleurotus ostreatus has hepatoprotective and nephroprotective properties, as evidenced by the significant inhibition of APAP-induced changes in liver and kidney histopathology, biochemical parameters, antioxidant enzymatic activities, and lipid peroxidation products. We further show that the antioxidant properties may, at least in part, elucidate the underlying mechanism.

In the present study we demonstrated that the administration of high doses of paracetamol significantly increased serum levels of acute liver damage indicators. The serum levels of GDH, ALT and AST were significantly elevated following paracetamol administration. GDH is a key enzyme in amino acid oxidation and a potential biomarker of drug-induced hepatic toxicity [38]. In common with GDH, serum ALT is considered to be a significant indicator of acute liver damage [39]. These enzymes are present in the hepatocyte cytoplasm; therefore, damaged hepatocytes release their contents including GDH, ALT and AST into the extracellular space. The released enzymes ultimately enter the circulation and thereby increase the serum levels. Treatment with Pleurotus ostreatus protected the liver against paracetamol induced hepato-cellular injury. This was evident by the decrease in serum GDH, ALT and AST activities. The observed hepato-protective effect might be a consequence of the amelioration of the underlying mechanisms by which APAP cause cellular damage, with subsequent suppression of the leakage of these enzymes into the blood.

Our results also revealed significant renal impairment in animals treated with paracetamol, demonstrated by the increase in serum creatinine and BUN, and urinary KIM-1 levels. High doses of paracetamol have been shown to cause acute and chronic renal failure in experimental animals. The mechanism involved included deficits in the antioxidant defense mechanisms, and lipid peroxidation in renal tissue [40]. Recent work has demonstrated the potential role of KIM-1 as a sensitive and specific tissue biomarker. KIM-1 is thought to improve the early detection of acute kidney injury following the exposure to 

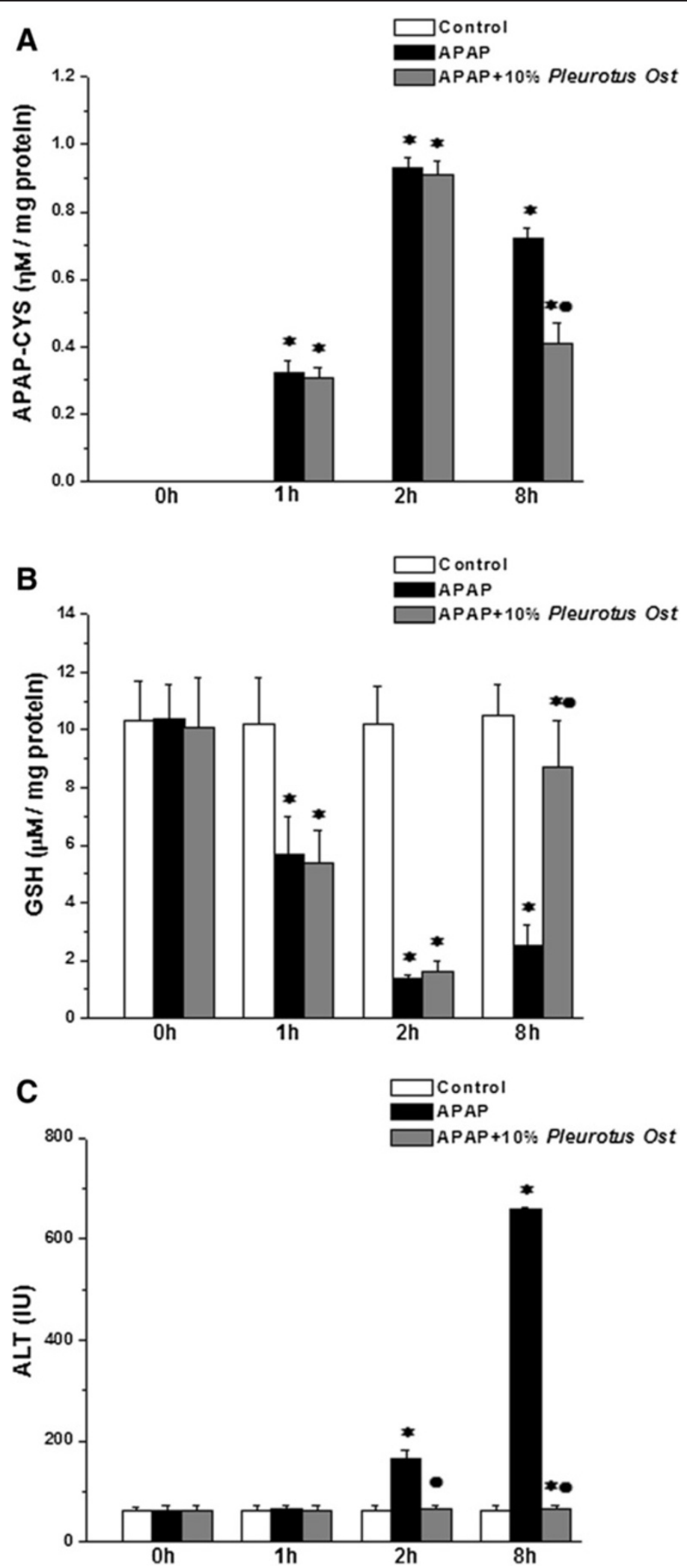

Figure 4 (See legend on next page.) 
(See figure on previous page.)

Figure 4 Effects of Pleurotus ostreatus on APAP-CYS adduct formation and GSH depletion. (A) APAP-CYS adduct level in liver tissue homogenate at $0,1,2$ and 8 hours post APAP or saline pre-treatment in control (white column), APAP treated (black column) and APAP $+10 \%$ Pleurotus ostreatus treated (grey column) groups. (B) GSH level in liver tissue homogenate at 0, 1, 2 and 8 hours post APAP or saline pre-treatment in control (white column), APAP treated (black column) and APAP + 10\% Pleurotus ostreatus treated (grey column) groups. (C) Serum ALT levels at 0, 1,2 and 8 hours post APAP or saline pre-treatment in control (white column), APAP treated (black column) and APAP $+10 \%$ Pleurotus ostreatus treated (grey column) groups. (Significant $=p<0.05$, *significant when compared to the corresponding control group at the same time point, $\cdot$ significant when compared to the corresponding APAP treated group at the same time point. Number of mice $=5 /$ group).

nephrotoxic compounds [41]. In the present study, we showed evidence for potential nephro-protective properties of Pleurotus ostreatus. Administration of Pleurotus ostreatus significantly reduced the increased serum creatinine and urinary KIM-1 to normal levels. Our findings, thus far, showed that Pleurotus ostreatus can oppose the injurious effects caused by high doses of APAP in the kidneys as well as the liver.

Histopathology findings confirmed the protective effect of Pleurotus ostreatus against APAP-induced liver and kidney damage. The histological appearance of the liver and kidney in the control group appeared normal. APAP treatment caused centrilobular necrosis, fatty changes (steatosis) and scattered lymphocytes infiltrate in hepatic parenchyma. Administration of APAP provoked renal proximal tubular coagulative necrosis and hemorrhage. It has been reported previously that APAP over-dose causes ultrastructural changes in the liver and kidneys $[42,43]$. Following Pleurotus ostreatus administration, as shown in Figures 1D and 2D, the majority of liver and kidney tissues preserved their normal architecture with minimal inflammatory changes. Based on our findings, it is clear that of Pleurotus ostreatus can avert APAPdependent cellular damage, thus preserving both the morphology and the function of liver and the kidneys. We were excited then to elucidate the underlying mechanisms.

Considerable progress has been made in animal models toward understanding the mechanisms of APAP toxicity. The majority of the therapeutic dose $(>90 \%)$ of APAP is glucuronidated or sulfated and then excreted. A small percentage is metabolized by cytochrome $\mathrm{P} 450$ enzymes (CYP), in both the liver and the kidney, to the reactive intermediate $\mathrm{N}$-acetyl-p-benzoquinone imine (NAPQI), which is readily detoxified by conjugation with glutathione (GSH) [44,45]. From rodent studies, we know that higher doses of paracetamol saturate the glucuronidation and sulfation pathways, resulting in formation of excess NAPQI. The additional reactive metabolite depletes liver GSH and binds to proteins [46,47]. Toxic doses of APAP could cause changes in the morphology and function of liver mitochondria $[48,49]$. It was suggested that NAPQI binding to mitochondrial proteins leads to mitochondrial oxidative stress. It is now known that this causes the mitochondrial membrane permeability transition (MPT) pore opening, matrix swelling, and outer membrane lysis in rodent models [42,50-52]. The permeabilization and lysis result in the release of apoptosis-inducing factor (AIF) and endonuclease G (EndoG) from mitochondria. These endonucleases translocate to nuclei and cause nuclear DNA fragmentation. Proapoptotic proteins, including cytochrome c and Smac/DIABLO, are also released. The end result is centrilobular hepatocyte necrosis and liver failure [8].

Table 1 The macro-components ( $\mathrm{g} / 100 \mathrm{~g}$ dried extract) and amino acids constituents ( $\mathrm{mg} / \mathrm{g}$ weight) of dried Pleurotus ostreatus

\begin{tabular}{|c|c|}
\hline Macro-components & $\mathrm{g} / 100 \mathrm{~g}$ dried extract \\
\hline Water & $5.23 \pm 0.29$ \\
\hline Protein & $28.15 \pm 0.46$ \\
\hline Fat & $0.38 \pm 0.02$ \\
\hline Total Dietary Fiber & $23.40 \pm 0.05$ \\
\hline Carbohydrates & $49.30 \pm 0.13$ \\
\hline Ash & $4.90 \pm 0.05$ \\
\hline Amino acids constituents & w/w\% protein \\
\hline Alanine & 7.66 \\
\hline Arginine & 12.66 \\
\hline Glutamic acid & 19.01 \\
\hline Methionine ${ }^{*}$ & 2.52 \\
\hline Lecuine $^{*}$ & 4.93 \\
\hline Isoleucine ${ }^{*}$ & 2.45 \\
\hline Aspartic acid & 9.78 \\
\hline Glycine & 4.93 \\
\hline Histidine $^{*}$ & 2.88 \\
\hline Lysine $^{*}$ & 3.50 \\
\hline Histidine & 2.70 \\
\hline Norvaline & 0.66 \\
\hline Phenylalanine* & 3.58 \\
\hline Proline & 2.48 \\
\hline Serine & 5.40 \\
\hline Valine $^{*}$ & 5.40 \\
\hline Threonine $^{*}$ & 5.00 \\
\hline Tryptophan* & 1.39 \\
\hline Tyrosine & 3.07 \\
\hline
\end{tabular}

${ }^{*}$ Essential amino acid. 
Oxidative stress has been suggested to play a critical role in cellular toxicity, as well as the pathophysiology several diseases. When the generation of ROS overcomes the antioxidant capacity, the free radicals can then interact with endogenous macromolecules and alter the cellular functions and even integrity. In the present study, high doses of APAP caused a significant rise in MDA and reduction in GSH levels in mice hepatic and renal tissues, with simultaneous inhibition of the antioxidant enzymes GSH-Px and SOD. Lipid peroxidation is a wellestablished mechanism of cellular injury. Lipid hydroperoxides are byproducts of lipid peroxidation, and increased levels of lipid peroxidation products are associated with a variety of chemical-induced toxicities including APAP. Lipid hydroperoxides are known to cause cellular injury by inactivation of membrane enzymes and receptors, depolymerizaton of polysaccharide, as well as protein cross linking and fragmentation [8]. A rapid depletion of GSH and lipid peroxidation has been also reported in both liver [53] and kidney [40] of animals treated with high doses of paracetamol. Paracetamol toxicity in the liver is mainly mediated by the covalent binding of NAPQI, the reactive metabolite of paracetamol, to sulfhydryl groups of GSH, and other cellular proteins and their subsequent oxidation. Overproduction of free radicals in the paracetamol treated mice may have triggered lipid peroxidation, and consequently increased MDA contents. This may also explain the diminished GSH contents; as to combat the increased formation of free radicals GSH stores might have been depleted. Decrease in GSH content can simultaneously decrease the activities of antioxidant enzymes such as GSH-Px, SOD and glutathione-Stransferase (GST) [4]. Administration of Pleurotus ostreatus significantly ameliorated the paracetamol-induced increase in MDA level and depletion of GSH contents toward normal values, with restoration of GSH-Px and SOD normal activities.

We validated the anti-oxidant properties of Pleurotus ostreatus by measuring APAP protein adducts formation and GSH levels in liver tissue homogenate. It is well known that APAP metabolic activation results in the formation of the reactive metabolite NAPQI, which reacts with GSH and with cysteine (CYS) residues on proteins [9]. Therefore, early GSH depletion kinetics (0-1 hour) may provide a logical proof on whether treatment with Pleurotus ostreatus prevents the metabolic activation of APAP or not. As illustrated by the kinetics (Figure 4), there was no significant difference in GSH depletion between mice treated with APAP and vehicle or APAP and Pleurotus ostreatus $60 \mathrm{~min}$ after APAP overdose suggesting that Pleurotus ostreatus had no impact on the metabolic activation of APAP. However, later kinetics (8 hours) demonstrated that Pleurotus ostreatus resulted in substantial reduction in overall protein adduct formation suggesting that an anti-oxidant incident opposed APAP-induced oxidative stress. Characterization of the mushroom extract (Table 1) revealed the presence of both essential and non-essential amino acids as tabulated (Table 1). Tyrosine, histidine, lysine and tryptophan, are generally accepted as antioxidants. Methionineis is a sulfur-containing antioxidant amino acid with well established clinically relevant anti-oxidant properties [54]. The presence of all these amino acids provides Pleurotus ostreatus with substantially a potent antioxidant capacity.

\section{Conclusion}

In summary, mitochondria are prominent targets for the toxicity of several molecules, including APAP. Mitochondrial dysfunction results in the impairment of energy metabolism and an intracellular oxidative stress with excessive formation of ROS. The antioxidant properties of Pleurotus ostreatus opposed mitochondrial dysfunction, and protected the liver and kidney tissues against APAP-induced acute inflammation.

\section{Competing interests}

The authors declare that they have no competing interests.

\section{Authors' contributions}

YMN carried out the oxidant-antioxidant studies, participated in the study design and coordination, performed the statistical analysis and drafted the manuscript. RMA carried out the biochemical studies and helped to draft the manuscript. RMS performed the histopathology studies and helped to draft the manuscript. MFS performed the characterization of the mushroom and participated in the design of the study. All authors read and approved the final manuscript.

\section{Acknowledgement}

Authors wish to thank Menoufia and Sadat City Universities for providing all required facilities.

\section{Author details}

${ }^{1}$ Department of Clinical Physiology, Faculty of Medicine, Menoufia University, Menoufia, Egypt. Department of Medical Biochemistry, Faculty of Medicine, Menoufia University, Menoufia, Egypt. ${ }^{3}$ Department of Pathology, Faculty of Medicine, Menoufia University, Menoufia, Egypt. ${ }^{4}$ Genetic Engineering and Biotechnology Research Institute, Sadat City University, Menoufia, Egypt.

Received: 10 March 2014 Accepted: 10 December 2014

Published: 15 December 2014

\section{References}

1. Gum SI, Cho MK: Recent updates on acetaminophen hepatotoxicity: the role of nrf2 in hepatoprotection. Toxicol Res 2013, 29(3):165-172.

2. Whitcomb DC: Acetaminophen poisoning and liver function. $N$ Engl J Med 1994, 331(19):1311-1312

3. Whitcomb DC, Block GD: Association of acetaminophen hepatotoxicity with fasting and ethanol use. JAMA 1994, 272(23):1845-1850.

4. Jaeschke H, McGill MR, Ramachandran A: Oxidant stress, mitochondria, and cell death mechanisms in drug-induced liver injury: lessons learned from acetaminophen hepatotoxicity. Drug Metab Rev 2012, 44(1):88-106.

5. McGill MR, Williams CD, Xie Y, Ramachandran A, Jaeschke $H$ : Acetaminophen-induced liver injury in rats and mice: comparison of protein adducts, mitochondrial dysfunction, and oxidative stress in the mechanism of toxicity. Toxicol Appl Pharmacol 2012, 264(3):387-394.

6. Bonkovsky HL, Kane RE, Jones DP, Galinsky RE, Banner B: Acute hepatic and renal toxicity from low doses of acetaminophen in the absence of alcohol abuse or malnutrition: evidence for increased susceptibility to 
drug toxicity due to cardiopulmonary and renal insufficiency. Hepatology (Baltimore, Md) 1994, 19(5):1141-1148.

7. Satirapoj B, Lohachit P, Ruamvang T: Therapeutic dose of acetaminophen with fatal hepatic necrosis and acute renal failure. J Med Assoc Thai 2007, 90(6):1244-1247.

8. McGill MR, Sharpe MR, Williams CD, Taha M, Curry SC, Jaeschke H: The mechanism underlying acetaminophen-induced hepatotoxicity in humans and mice involves mitochondrial damage and nuclear DNA fragmentation. J Clin Investig 2012, 122(4):1574-1583.

9. Dimova S, Hoet PH, Dinsdale D, Nemery B: Acetaminophen decreases intracellular glutathione levels and modulates cytokine production in human alveolar macrophages and type II pneumocytes in vitro. Int J Biochem Cell Biol 2005, 37(8):1727-1737.

10. Dimova S, Hoet PH, Nemery B: Paracetamol (acetaminophen) cytotoxicity in rat type II pneumocytes and alveolar macrophages in vitro. Biochem Pharmacol 2000, 59(11):1467-1475.

11. Stern ST, Bruno MK, Horton RA, Hill DW, Roberts JC, Cohen SD: Contribution of acetaminophen-cysteine to acetaminophen nephrotoxicity II. Possible involvement of the gamma-glutamyl cycle. Toxicol Appl Pharmacol 2005, 202(2):160-171.

12. Askari F, Rashidkhani B, Hekmatdoost A: Cinnamon may have therapeutic benefits on lipid profile, liver enzymes, insulin resistance, and high-sensitivity C-reactive protein in nonalcoholic fatty liver disease patients. Nutr Res 2013, 34(2):143-148.

13. Capellini VK, Celotto AC, Baldo CF, Olivon VC, Viaro F, Rodrigues AJ, Evora PR: Diabetes and vascular disease: basic concepts of nitric oxide physiology, endothelial dysfunction, oxidative stress and therapeutic possibilities. Curr Vasc Pharmacol 2010, 8(4):526-544.

14. Fiorentino TV, Prioletta A, Zuo P, Folli F: Hyperglycemia-induced oxidative stress and its role in diabetes mellitus related cardiovascular diseases. Curr Pharm Des 2013, 19(32):5695-5703.

15. Manna P, Sil PC: Impaired redox signaling and mitochondrial uncoupling contributes vascular inflammation and cardiac dysfunction in type 1 diabetes: protective role of arjunolic acid. Biochimie 2012, 94(3):786-797.

16. Moraes TB, Dalazen GR, Jacques CE, de Freitas RS, Rosa AP, Dutra-Filho CS: Glutathione metabolism enzymes in brain and liver of hyperphenylalaninemic rats and the effect of lipoic acid treatment. Metab Brain Dis 2014, 29(2):609-615.

17. Sedeek M, Nasrallah R, Touyz RM, Hebert RL: NADPH oxidases, reactive oxygen species, and the kidney: friend and foe. J Am Soc Nephrol 2013, 24(10):1512-1518.

18. Chen J: Heme oxygenase in neuroprotection: from mechanisms to therapeutic implications. Rev Neurosci 2014, 25(2):269-280.

19. Chen YR, Zweier JL: Cardiac mitochondria and reactive oxygen species generation. Circ Res 2014, 114(3):524-537.

20. Uttara B, Singh AV, Zamboni P, Mahajan RT: Oxidative stress and neurodegenerative diseases: a review of upstream and downstream antioxidant therapeutic options. Curr Neuropharmacol 2009, 7(1):65-74.

21. Wasser SP: Current findings, future trends, and unsolved problems in studies of medicinal mushrooms. Appl Microbiol Biotechnol 2011, 89(5):1323-1332

22. Anandhi R, Annadurai T, Anitha TS, Muralidharan AR, Najmunnisha K, Nachiappan V, Thomas PA, Geraldine P: Antihypercholesterolemic and antioxidative effects of an extract of the oyster mushroom, Pleurotus ostreatus, and its major constituent, chrysin, in Triton WR-1339induced hypercholesterolemic rats. J Physiol Biochem 2013, 69(2):313-323.

23. Jedinak A, Sliva D: Pleurotus ostreatus inhibits proliferation of human breast and colon cancer cells through p53-dependent as well as p53-independent pathway. Int J Oncol 2008, 33(6):1307-1313.

24. Jesenak M, Majtan J, Rennerova Z, Kyselovic J, Banovcin P, Hrubisko M: Immunomodulatory effect of pleuran (beta-glucan from Pleurotus ostreatus) in children with recurrent respiratory tract infections. Int Immunopharmacol 2013, 15(2):395-399.

25. Trzebska-Jeske I, Rutkowska U, Zielinska Z: [Comparison of the methods of estimating the energy value of cooked meals]. Rocz Panstw Zakl Hig 1979, 30(3):277-284

26. Asp NG, Johansson CG, Hallmer H, Siljestrom M: Rapid enzymatic assay of insoluble and soluble dietary fiber. J Agric Food Chem 1983, 31(3):476-482.

27. Bidlingmeyer BA, Cohen SA, Tarvin TL: Rapid analysis of amino acids using pre-column derivatization. J Chromatogr 1984, 336(1):93-104.
28. Muldrew KL, James LP, Coop L, McCullough SS, Hendrickson HP, Hinson JA, Mayeux PR: Determination of acetaminophen-protein adducts in mouse liver and serum and human serum after hepatotoxic doses of acetaminophen using high-performance liquid chromatography with electrochemical detection. Drug Metab Dispos 2002, 30(4):446-451.

29. Lindena J, Trautschold I: Catalytic enzyme activity concentration in plasma of man, sheep, dog, cat, rabbit, guinea pig, rat and mouse. Approach to a quantitative diagnostic enzymology, I. Communication. J Clin Chem Clin Biochem 1986, 24(1):11-18.

30. Perrone RD, Madias NE, Levey AS: Serum creatinine as an index of renal function: new insights into old concepts. Clin Chem 1992, 38(10):1933-1953.

31. Schumann G, Aoki R, Ferrero CA, Ehlers G, Ferard G, Gella FJ, Jorgensen PJ, Kanno T, Kessner A, Klauke R, Kristiansen N, Lessinger JM, Linsinger TP, Misaki H, Mueller MM, Panteghini M, Pauwels J, Schiele F, Schimmel HG, Vialle A, Weidemann G, Schumann G: International Federation of Clinical Chemistry and Laboratory Medicine: IFCC primary reference procedures for the measurement of catalytic activity concentrations of enzymes at 37 degrees C. Clin Chem Lab Med 2006, 44(9):1146-1155.

32. Ichimura T, Hung CC, Yang SA, Stevens $J$, Bonventre JV: Kidney injury molecule-1: a tissue and urinary biomarker for nephrotoxicant-induced renal injury. Am J Physiol 2004, 286(3):F552-F563.

33. Zhou Y, Vaidya VS, Brown RP, Zhang J, Rosenzweig BA, Thompson KL, Miller TJ, Bonventre JV, Goering PL: Comparison of kidney injury molecule-1 and other nephrotoxicity biomarkers in urine and kidney following acute exposure to gentamicin, mercury, and chromium. Toxicol Sci 2008, 101(1):159-170.

34. Jacobson B, Quigley G, Lockitch G: Adaptation of glutathione peroxidase assay to the Technicon RA-1000. Clin Chem 1988, 34(10):2164-2165.

35. Kuthan $H$, Haussmann $H J$, Werringloer J: A spectrophotometric assay for superoxide dismutase activities in crude tissue fractions. Biochem J 1986, 237(1):175-180.

36. Satoh K: Serum lipid peroxide in cerebrovascular disorders determined by a new colorimetric method. Clin Chim Acta 1978, 90(1):37-43.

37. Wang XJ, Sun Z, Chen W, Eblin KE, Gandolfi JA, Zhang DD: Nrf2 protects human bladder urothelial cells from arsenite and monomethylarsonous acid toxicity. Toxicol Appl Pharmacol 2007, 225(2):206-213.

38. O'Brien PJ, Slaughter MR, Polley SR, Kramer K: Advantages of glutamate dehydrogenase as a blood biomarker of acute hepatic injury in rats. Lab Anim 2002, 36(3):313-321.

39. Ozer J, Ratner M, Shaw M, Bailey W, Schomaker S: The current state of serum biomarkers of hepatotoxicity. Toxicology 2008, 245(3):194-205.

40. Ghosh J, Das J, Manna P, Sil PC: Acetaminophen induced renal injury via oxidative stress and TNF-alpha production: therapeutic potential of arjunolic acid. Toxicology 2010, 268(1-2):8-18.

41. Sabbisetti VS, Ito K, Wang C, Yang L, Mefferd SC, Bonventre JV: Novel assays for detection of urinary KIM-1 in mouse models of kidney injury. Toxicol Sci 2012, 131(1):13-25.

42. Placke ME, Ginsberg GL, Wyand DS, Cohen SD: Ultrastructural changes during acute acetaminophen-induced hepatotoxicity in the mouse: a time and dose study. Toxicol Pathol 1987, 15(4):431-438.

43. Mazer M, Perrone J: Acetaminophen-induced nephrotoxicity: pathophysiology, clinical manifestations, and management. J Med Toxicol 2008, 4(1):2-6.

44. Blantz RC: Acetaminophen: acute and chronic effects on renal function. Am J Kidney Dis 1996, 28(1 Suppl 1):S3-S6.

45. Moon YJ, Wang X, Morris ME: Dietary flavonoids: effects on xenobiotic and carcinogen metabolism. Toxicol In Vitro 2006, 20(2):187-210.

46. Lauterburg BH, Mitchell JR: Toxic doses of acetaminophen suppress hepatic glutathione synthesis in rats. Hepatology (Baltimore, Md) 1982, 2(1):8-12.

47. Mitchell JR: Acetaminophen toxicity. N Engl J Med 1988, 319(24):1601-1602.

48. Meyers LL, Beierschmitt WP, Khairallah EA, Cohen SD: Acetaminophen-induced inhibition of hepatic mitochondrial respiration in mice. Toxicol Appl Pharmacol 1988, 93(3):378-387.

49. Panatto JP, Jeremias IC, Ferreira GK, Ramos AC, Rochi N, Goncalves CL, Daufenbach JF, Jeremias GC, Carvalho-Silva M, Rezin GT, Scaini G, Streck EL: Inhibition of mitochondrial respiratory chain in the brain of rats after hepatic failure induced by acetaminophen. Mol Cell Biochem 2011, 350(1-2):149-154

50. Kon K, Kim JS, Jaeschke H, Lemasters JJ: Mitochondrial permeability transition in acetaminophen-induced necrosis and apoptosis of cultured mouse hepatocytes. Hepatology (Baltimore, Md) 2004, 40(5):1170-1179. 
51. Masubuchi Y, Suda C, Horie T: Involvement of mitochondrial permeability transition in acetaminophen-induced liver injury in mice. J Hepatol 2005, 42(1):110-116.

52. Reid AB, Kurten RC, McCullough SS, Brock RW, Hinson JA: Mechanisms of acetaminophen-induced hepatotoxicity: role of oxidative stress and mitochondrial permeability transition in freshly isolated mouse hepatocytes. J Pharmacol Exp Ther 2005, 312(2):509-516.

53. Hinson JA, Reid AB, McCullough SS, James LP: Acetaminophen-induced hepatotoxicity: role of metabolic activation, reactive oxygen/nitrogen species, and mitochondrial permeability transition. Drug Metab Rev 2004, 36(3-4):805-822

54. Manna P, Das J, Sil PC: Role of sulfur containing amino acids as an adjuvant therapy in the prevention of diabetes and its associated complications. Curr Diabetes Rev 2013, 9(3):237-248.

doi:10.1186/1472-6882-14-494

Cite this article as: Naguib et al:: Pleurotus ostreatus opposes mitochondrial dysfunction and oxidative stress in acetaminophen-induced hepato-renal injury. BMC Complementary and Alternative Medicine 2014 14:494.

\section{Submit your next manuscript to BioMed Central and take full advantage of:}

- Convenient online submission

- Thorough peer review

- No space constraints or color figure charges

- Immediate publication on acceptance

- Inclusion in PubMed, CAS, Scopus and Google Scholar

- Research which is freely available for redistribution 